\title{
The morphogenesis of abnormal coronary arteries in the congenitally malformed heart
}

\author{
Robert H. Anderson, MD, PhD (Hon), FRCPath, FRCS Ed (Hon), Jasmin E. Turner, PhD, and \\ Deborah J. Henderson, PhD
}

\begin{abstract}
Feature Editor Note-The relentless work of evolution has resulted in well-formed coronary arteries. The normal and abnormal development of the coronary arteries is one of the most fascinating stories of evolution. Herein, a group of experts led by Professor Robert H. Anderson describe our current knowledge of the development of the coronary arteries. A proper understanding of the formation of the myocardial vasculature is important for surgeons operating on congenital cardiac anomalies, including patients with right ventricular-dependent coronary arteries, coronary fistulae, and other abnormalities of the coronary arborization. Furthermore, it is equally important for scientists working in the field of myocardial regeneration. Rapid advances in myocardial regeneration and recent explosive progress in gene-editing technology have enabled us to create large contractile myocardial patches and 3-dimensional myocardial structures to emulate cardiac chambers. A proper understanding of angiogenesis and vasculogenesis will become crucial to ensure the functionality and longevity of the stem-cell derived myocardium. After all, the best we can do in life is to learn and emulate the great work of nature!
\end{abstract}

\section{Igor E. Konstantinov, MD, PhD, FRACS}

Knowledge of development can aid in the understanding of the anatomy of congenital cardiac malformations, although gaps remain in making the transfer of information from those studying mechanisms of development to those working in the operating room. This is true when considering the link between the development of the coronary arteries and their abnormal arrangement in the setting of congenital cardiac disease. The coronary arteries themselves can be abnormal when the remainder of the heart is normally formed, such as the finding of the left coronary artery arising from the pulmonary trunk. ${ }^{1}$ In recent years, attention has focused on the origin of one of the coronary

From the Biosciences Institute, Newcastle University, Newcastle-upon-Tyne, United Kingdom.

Received for publication July 2, 2021; revisions received July 30, 2021; accepted for publication Aug 1, 2021; available ahead of print Oct 4, 2021.

Address for reprints: Robert H. Anderson, MD, PhD (Hon), FRCPath, FRCS Ed (Hon), 60 Earlsfield Rd, London SW18 3DN, United Kingdom (E-mail: sejjran@ucl.ac.uk).

J Thorac Cardiovasc Surg 2022;164:344-9

$0022-5223 / \$ 36.00$

Copyright (c) 2021 by The American Association for Thoracic Surgery

https://doi.org/10.1016/j.jtcvs.2021.08.084

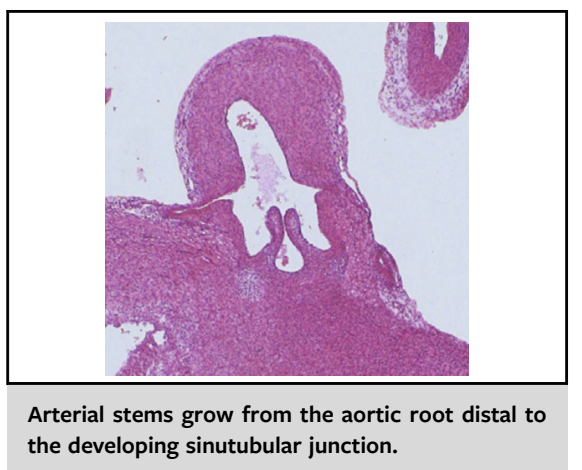

\begin{abstract}
CENTRAL MESSAGE
During development, coronary arterial stems grow out of the aortic root, joining a crown-like plexus, which feeds the epicardial vessels, and thence the intramural arteries
\end{abstract}

See Commentaries on pages 350 and 351.

arteries from an unexpected aortic valvar sinus. ${ }^{2}$ Much more frequently, the arteries are abnormally positioned in the setting of an intracardiac malformation, such as the variations noted by surgeons performing the arterial switch procedure. ${ }^{3}$ Other examples are the fistulous communications between the ventricular cavities and the epicardial coronary arteries, as found in hypoplastic left heart syndrome, or pulmonary atresia with intact ventricular septum. ${ }^{4}$ In all these settings, it can be argued that knowledge of development should serve to facilitate the understanding of the potential variations. In this review, we summarize our own knowledge of coronary arterial development, highlighting the potential links between development and the congenital lesions. Our investigations were all retrospective and anonymized and therefore did not require informed consent, in compliance with institutional ethical guidelines and the principles outlined in the Declaration of Helsinki.

\section{THE ORIGINS OF THE CORONARY ARTERIES}

The definitive coronary arteries are formed on the basis of their endothelial lining. Only later in development does this 
endothelial scaffold become surrounded by vascular smooth muscle, itself supported by a fibrous matrix continuous with the external adventitial layer. Doubt did exist as to whether the initial endothelial channels appeared by the process of angiogenesis, meaning that new cells proliferate from preexisting ones, as opposed to vasculogenesis, when the cells themselves are newly formed. Convincing molecular evidence now reveals the endothelial network to be formed predominantly by vasculogenesis. ${ }^{5}$ Angiogenesis could also be involved if there is outgrowth, as also suggested, from the systemic venous sinus. ${ }^{6}$ The origin of the endothelial linings themselves, nonetheless, remains a matter of debate. Some suggest that they derive from the lining of the ventricular trabeculations, ${ }^{7}$ others invoke the hepatic sinusoids, ${ }^{8}$ but it is now almost certainly the case that the epicardium is involved. ${ }^{9}$ Yet another concept, now achieving widespread recognition, suggests the vessels, initially derived from the systemic venous sinus, are reprogrammed to become arterial rather than venous. ${ }^{6}$ As already indicated, if proven, then this would substantiate a role also for angiogenesis. Taken together, the evidence suggests that the endothelial components derive from multiple sources. ${ }^{10}$

Equally important is the mechanism of their connection with the aortic root. It was long since suggested that, during normal development, stems grew out from both the developing aortic and pulmonary roots. ${ }^{11}$ Subsequently, it became accepted that the coronary arteries, rather than growing out from the aortic root, grew into the developing valvar sinuses. ${ }^{12}$ Emerging molecular findings now provide evidence to substantiate the concept of outgrowth of a short coronary arterial stem. ${ }^{13}$ Smooth muscle cells found in the arterial stems, furthermore, have been shown to derive from the neural crest, or from the second heart field. ${ }^{14,15}$ These, and other findings, such as the description of a "peritruncal plexus" in the avian heart, ${ }^{10}$ add further credence to the notion that the coronary arterial network is a developmental mosaic. ${ }^{16}$

In terms of providing the link between development and malformations, we emphasize the topics of the mechanism of connection of the epicardial coronary arteries to the aortic root, the formation of the arteries within the ventricular walls, and the connection between the mural meshwork and the epicardial arteries. This latter process is inextricably linked with the growth of the compact parts of the ventricular walls. This is another contentious topic. The compact component of the walls is still presumed by some to be formed by coalescence of previously formed trabeculations, ${ }^{17}$ which make up the greater parts of the walls during early development. There is no convincing evidence of which we are aware to support the notion of mural compaction. ${ }^{18}$ Our own burgeoning knowledge of the changes found in the developing human and murine hearts, nonetheless, does now permit us to speculate on normal as opposed to abnormal development.

\section{EVIDENCE FROM KNOWLEDGE OF DEVELOPMENT OF THE HUMAN HEART}

The key changes in human cardiac development span the period from the fifth through the eighth weeks subsequent to fertilization. At 8 weeks, the orifices of the coronary arteries have yet properly to be incorporated into the developing sinuses of the aortic root. The changes that occur during development of the aortic valvar sinuses, however, remain to be elucidated. The initial embryonic stages are dominated by the looping of the initial linear heart tube, with the apical components of the developing ventricles then expanding in series from the inlet and outlet parts of the loop. Subsequent to looping, the developing outflow tract, supported above the cavity of the right ventricle, has myocardial walls, which extend to the margins of the pericardial cavity. At this stage, the ventricular walls are formed mostly by a meshwork of the trabeculations, with only a thin compact layer, and no formation of epicardial coronary arteries. The ventricular cardiomyocytes are presumably nourished directly from the ventricular cavities.

The subsequent steps in development revolve around the remodeling of the outflow tract. The most convincing evidence regarding these changes is based on knowledge of cardiac development in the mouse. Further cells from the heart-forming fields are subsequently added to the outflow tract, but they do not differentiate to become myocardial. Instead, they form the intrapericardial components of the arterial trunks, differentiating to become smooth muscle and fibrous cells. ${ }^{19,20}$ Formation and separation of the intrapericardial arterial trunks makes it possible to recognize the developing arterial roots, which form within the middle part of the outflow tract, surrounded by a collar of outflow myocardium (Figure 1, A). The myocardial collar contains the endothelial channels that will eventually provide the bridge between the epicardial coronary arteries and the aortic root. The precise role of these endocardial channels, described as the peritruncal plexus, and which develop first in the walls of the distal non-myocardial outflow tract, ${ }^{10,21}$ remains to be clarified. At the stage of appearance of these vascular channels, the ventricular walls themselves remain formed predominantly by the meshwork of trabeculations.

By this stage, which represents around 7 weeks of human development, significant changes have also taken place within the ventricular part of the heart. Fusion of the initially undivided cushions found proximally within the outflow tract (Figure 1,A) creates a shelf in the roof of the right ventricle. Closure of the persisting channel between the developing aortic root and the right ventricle by tubercles derived from the atrioventricular cushions produces the membranous part of the septum. This completes 


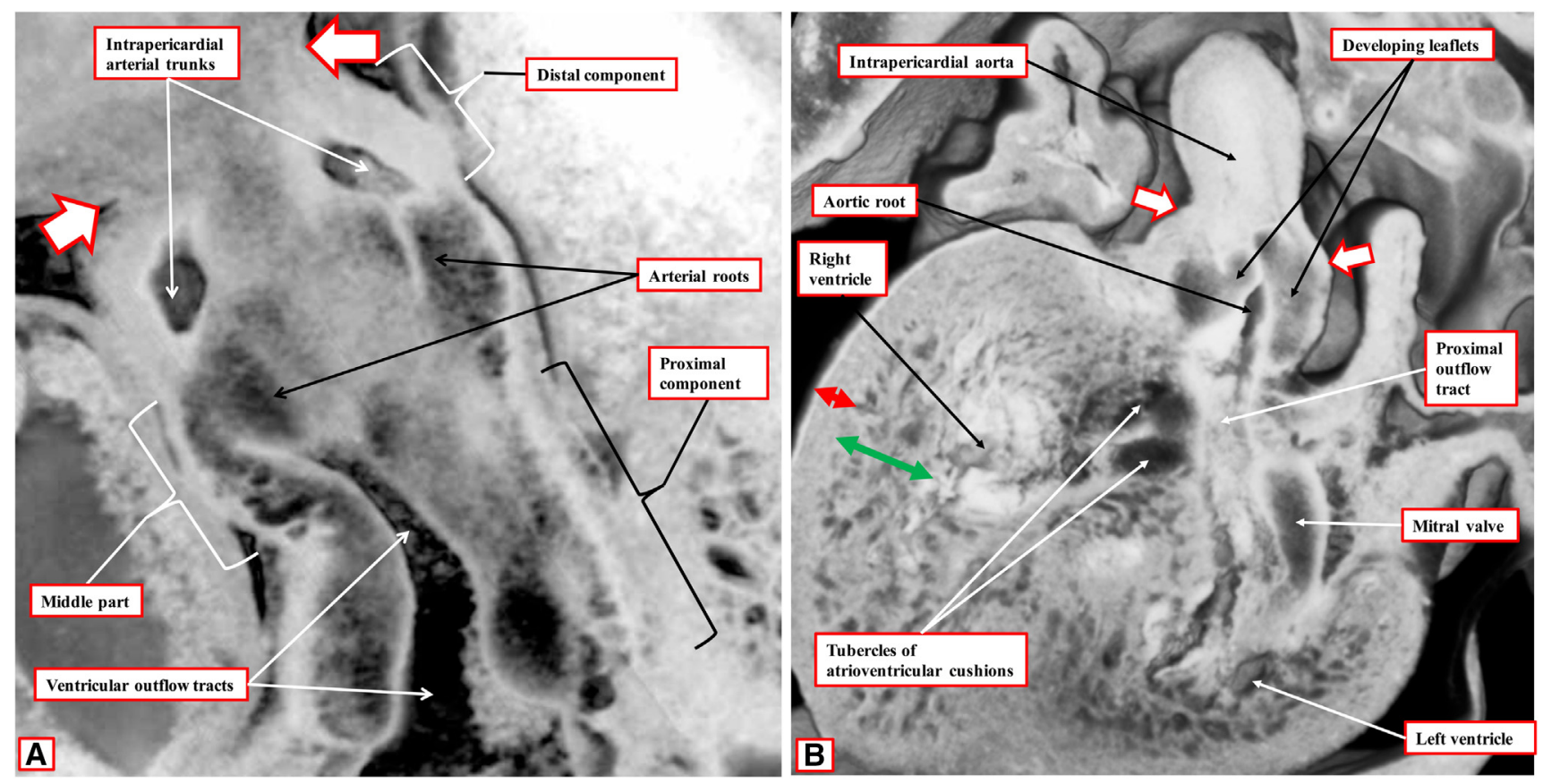

FIGURE 1. The images show the stages in maturation of the developing outflow tract in the human heart, as revealed by interrogation of 3-dimensional episcopic datasets. A, Frontal section through the tripartite outflow tract at Carnegie stage 16, when the embryo is around 6 weeks old. The white arrows with red borders show the margins of the pericardial cavity. B, Sagittal section through the left ventricle and aortic root at Carnegie stage 19, which is toward the end of the seventh week of development. The white arrows with red borders show the distal margin of the myocardium of the middle part of the outflow tract, which still surrounds the greater part of the aortic root. The red and green double-headed arrows show that, at this stage, the ventricular walls are largely made up of the trabecular layer (green arrow), with a relatively thin compact layer (red arrow).

the process of ventricular septation (Figure 1,B). Even at this stage, the myocardium of the middle outflow tract, containing its endothelial channels, surrounds the larger parts of the developing arterial roots, and the ventricular walls remain largely trabeculated. And still there has been no formation on any epicardial vascular channels, nor arterial channels within the thin compact ventricular walls. Only when the embryo is at the beginning of the eighth week of development can vascular channels be recognized in the developing atrioventricular and interventricular grooves. Examination of the material at our disposal reveals that an extensive crown-like endothelial plexus can now be recognized in the myocardial covering of the middle part of the outflow tract.

The channels in the atrioventricular and interventricular grooves, which will form the major epicardial arteries, have no connection with the aortic root at the illustrated stage of development (Figure 1,B). Shortly after this stage, nonetheless, it is possible to recognize the endothelial stems of the right and left coronary arteries. They grow out of the aorta distal to the myocardial border, at a stage when there has been scant formation of the nonmyocardial walls of the aortic valvar sinuses (Figures 2 and 3 ). They originate distal to the level that will become the sinutubular junctions, merging with the crown-like plexus formed in circumferential fashion in the middle part of the outflow tract. This plexus then provides the bridge with the developing epicardial vessels.

The ventricular walls have begun to thicken by this stage, but the trabecular meshwork remains prominent, with no obvious formation of arterial channels within the developing compact component. It is in the fetal period, during the ninth and tenth weeks, that the nonmyocardial walls of the arterial valvar sinuses become incorporated into the aortic root. Only with maturation of the sinuses do the orifices of the right and left coronary arteries assume their definitive positions proximal to the sinutubular junctions. At the same time, the epicardial coronary arteries establish their communications with the mural arterial meshwork, albeit that the details of these processes remain to be clarified. With these changes, nonetheless, the nourishment of the developing ventricular walls becomes dependent on the circulation from the aortic root.

\section{THE EVIDENCE AVAILABLE FROM CARDIAC DEVELOPMENT IN THE MOUSE}

Our access to datasets from mouse embryos and fetuses prepared using the technique of episcopic microscopy confirm that, as described for the human heart, the outflow tract develops with proximal, middle, and distal parts. Marking experiments then confirm that the middle part has retained its myocardial walls until the stage of closure of 

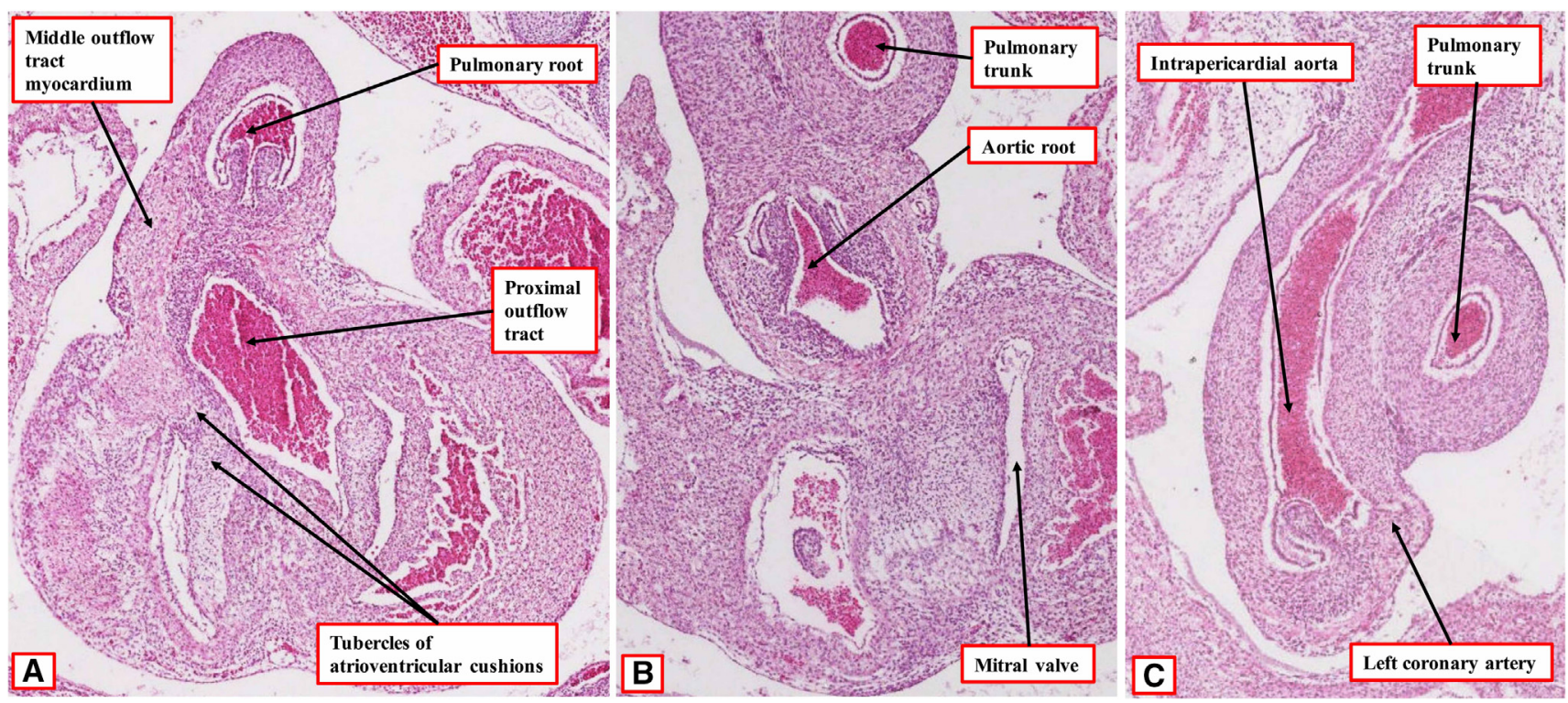

FIGURE 2. The images show serial histologic sections, stained with hematoxylin and eosin, from a human embryo at Carnegie stage 22 , which is during the eighth week of development. A, Outflow tract formed in the roof of the right ventricle, which has been closed by the tubercles of the atrioventricular cushions. The outflow tract retains its myocardial walls. Endothelial channels within these walls will eventually provide the bridge with the epicardial arterial trunks. B, Developing aortic root, which remains enclosed in the myocardial walls of the middle part of the outflow tract. C, Long-axis cut through the intrapericardial aorta. The stem of the left coronary artery can be seen growing out of the tubular aorta distal to what will become the sinutubular junction.

the embryonic interventricular communication (Figure $4, A$ ). Only at this stage is it possible to identify the outgrowth of endothelial stems from the intrapericardial aortic trunk, which originate as in the human heart distal to the myocardial border (Figure 4, $B$ and $C$ ). Ongoing maturation of the aortic valvar sinuses permits the coronary arterial orifices
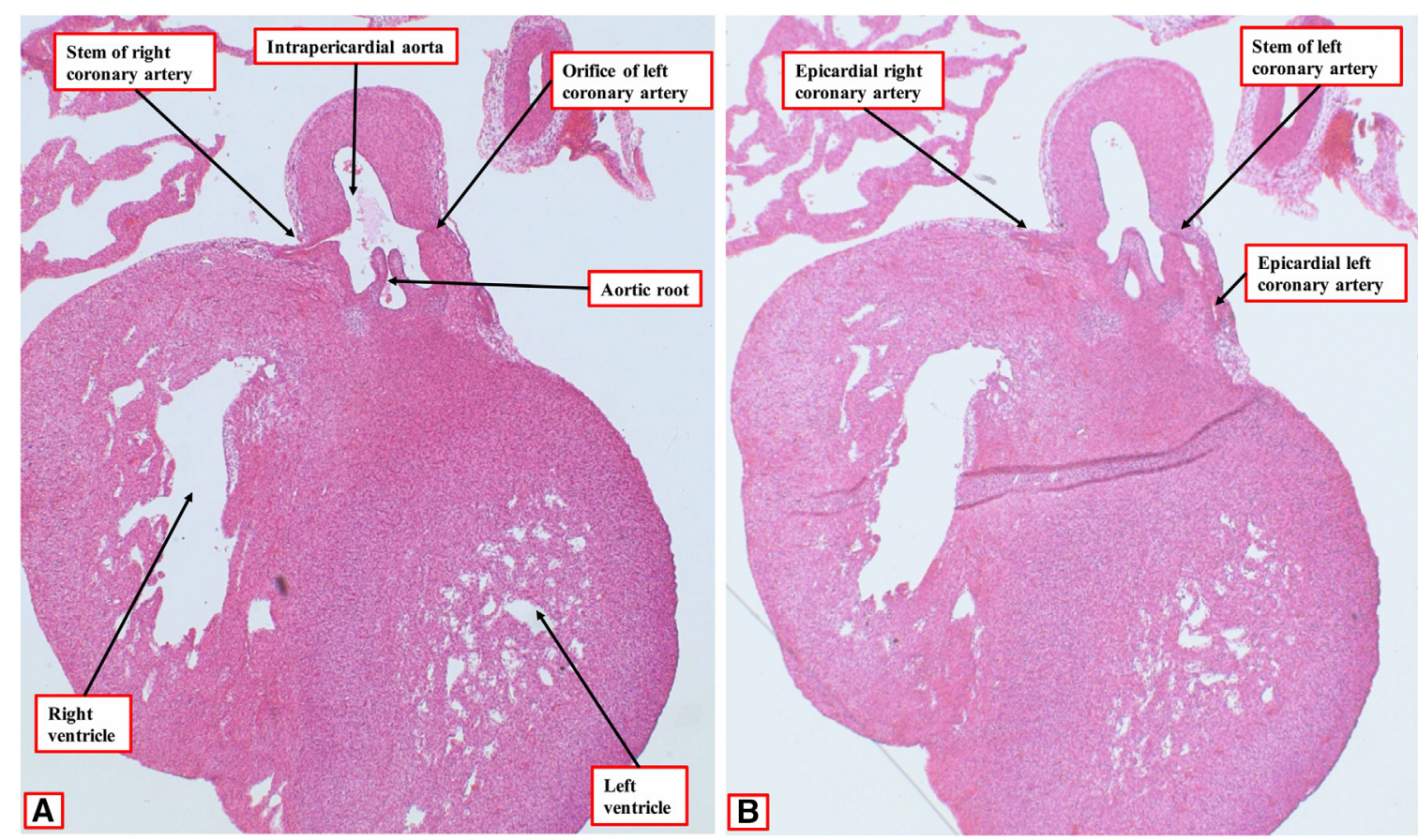

FIGURE 3. The images are histologic sections from a human embryo at 8 weeks of development, which is the first week of the fetal stage of development. The compact components of the ventricular walls are beginning to thicken, but there are still multiple trabeculations filling the ventricular cavities. Panel A shows how the arterial stems of both coronary arteries can be recognized as growing out of the tubular intrapericardial aorta distal to what will become the sinutubular junction. As can be seen in B, the left coronary artery takes a right-angled bend as it turns to make contact with the epicardial component of the left coronary artery. 

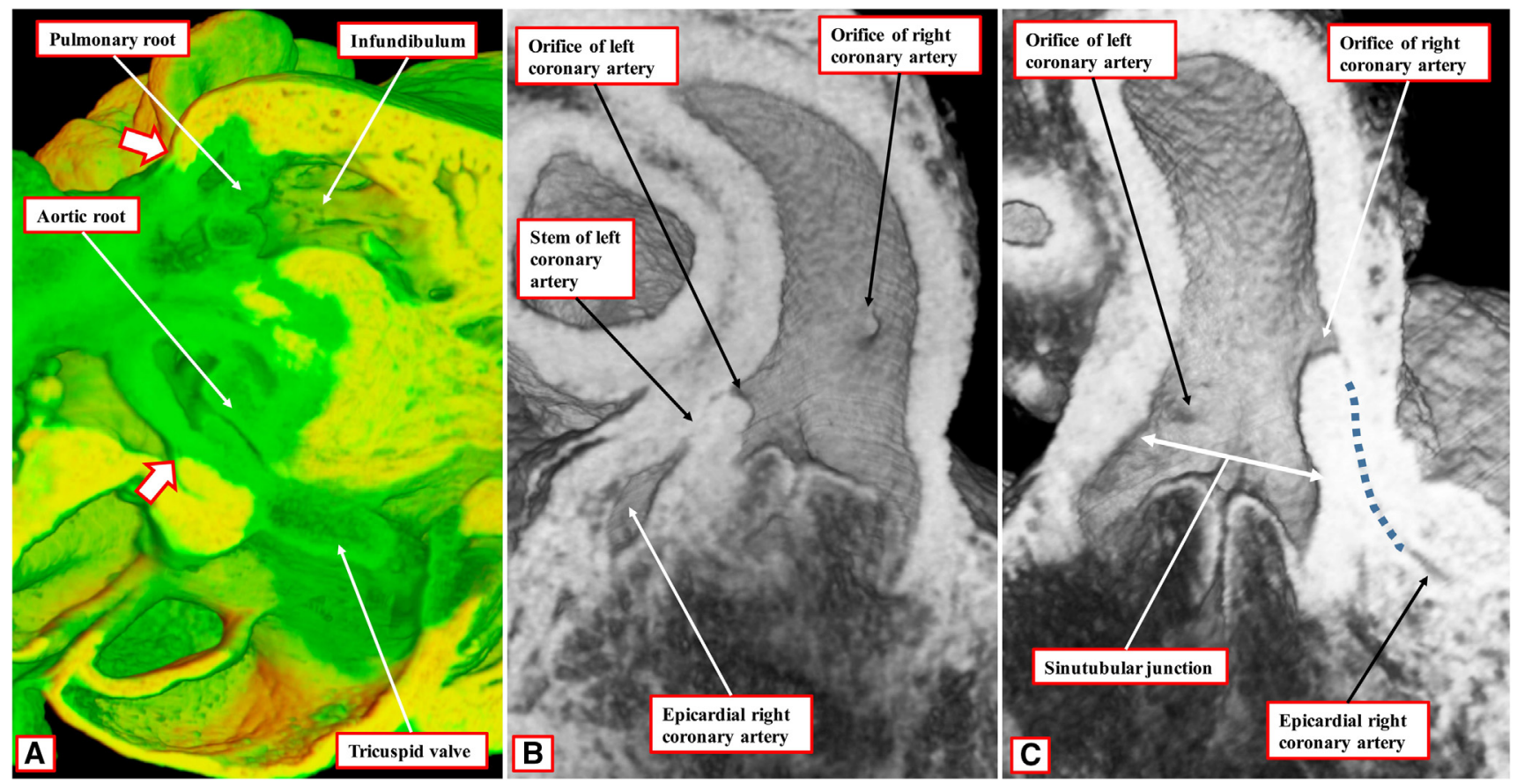

FIGURE 4. The images show the features of the developing aortic root in the mouse heart, as revealed by interrogation of datasets prepared by episcopic microscopy. The dataset shown in (A) is from a mouse, sacrificed at embryonic day 13.5, genetically modified to show the extent of the myocardium, which is colored yellow. The white arrows with red borders show that distal extent of the outflow tract myocardium, which surrounds the larger parts of the developing aortic and pulmonary roots. B and C, The orifices of the coronary arteries, both of which are distal to the developing sinutubular junction. The black dotted line in (C) shows the extensive track, which joins the orifice with the epicardial coronary artery present within the myocardial covering of the aortic root.

to assume their definitive location proximal to the sinutubular junction. At the same time, there is thickening of the compact components of the ventricular walls, with reciprocal diminution in the thickness of the trabecular layer.

\section{SIGNIFICANCE OF THE DEVELOPMENTAL CHANGES TO CONGENITAL MALFORMATIONS}

We have emphasized the separate steps of the appearance of the major epicardial arteries, their connection with the aortic root, and the development of the intramural arterial plexuses. All these changes take place at, and after, the end of the embryonic period of development. The compact component of the ventricular walls thickens during this period, but not by a process of "compaction." Instead, the trabecular component becomes less prominent, while the compact wall thickens by proliferation of cardiomyocytes. At the end of the embryonic period, the arterial roots still remain largely enclosed within a myocardial turret. It is the turret that contains the extensive crown-like plexus of developing endothelial channels. These channels provide the potential for arteries to be formed in circumferential fashion relative to the arterial pedicles, a feature seen in markedly variable form in the setting of transposition. ${ }^{22}$ The stems of the coronary arteries, however, arise distal to the developing sinutubular junction. They use the circumferential plexus as a bridge to the major epicardial vessels. It is the epicardial vessels that then assume the role of nourishing the thickening ventricular walls, making their own connections with the developing intramural coronary arterial vessels.

An appreciation of these changes permits inferences to be made regarding the morphogenesis of the various lesions involving the coronary arteries. The initial location of the arterial orifices distal to the sinutubular junctions provides an obvious explanation for their high origin. ${ }^{23}$ Abnormal remodeling of the developing sinuses and leaflets then provides a rational explanation for abnormal aortic origin. ${ }^{2}$ Outgrowth of a stem from the pulmonary, rather than the aortic, root will account for abnormal pulmonary origin. ${ }^{3}$ The fistulous communications between the ventricular cavities and the epicardial arteries are found predominantly in lesions that are acquired diseased of fetal life, namely the hypoplastic left heart syndrome, and pulmonary atresia with intact ventricular septum. ${ }^{24}$ Evidence regarding the acquired nature of these communications comes from the fact that, in both settings, the fistulous communications are found only when the ventricular cavity itself is hypertensive, presumably in consequence of the hypertrophy of its walls. Thus, the fistulous communications found in the setting of pulmonary atresia are most frequent when mural hypertrophy has been sufficient to squeeze out the cavities of the apical and outlet ventricular components. In 
hypoplastic left heart syndrome, the fistulous communications are found only when the mitral valve is stenotic rather than atretic, with the associated fibroelastosis often masking the presence of microscopic communications. All of these features point to ongoing hypertrophy of the ventricular walls as a major determinant of these changes. The compact component of the walls, however, is not formed by "compaction." 18 This points to the danger of invoking the entrapment of trabecular endothelium as part of the normal process of development. The so-called "sinusoids" found in the setting of pulmonary atresia with intact septum, nonetheless, are likely derived from trabecular endothelium.

\section{CONCLUSIONS}

We have learned much over the past decade in regard to the laying down of the primordiums of the coronary arterial plexuses. ${ }^{16}$ As yet, this initial work has not properly been linked to the definitive appearance of the epicardial coronary arteries, nor their union with the developing aortic root. The mechanisms of formation of the plexuses within the compact myocardial ventricular walls have also to be elucidated. More work is required to refine our knowledge of these changes, which are inextricably linked with formation of the valvar sinuses. Only with this new knowledge will we finally provide an adequate explanation of the morphogenesis of abnormal coronary arteries.

\section{Conflict of Interest Statement}

The authors reported no conflicts of interest.

The Journal policy requires editors and reviewers to disclose conflicts of interest and to decline handling or reviewing manuscripts for which they may have a conflict of interest. The editors and reviewers of this article have no conflicts of interest.

The human histology images were provided by the Joint MRC/ Wellcome Trust (MR/R006237/1) Human Developmental Biology Resource (www.hdbr.org). ${ }^{25}$

\section{References}

1. Smith A, Arnold R, Anderson RH, Wilkinson JL, Qureshi SA, Gerlis LM, et al. Anomalous origin of the left coronary artery from the pulmonary trunk. Anatomic findings in relation to pathophysiology and surgical repair. J Thorac Cardiovasc Surg. 1989;98:16-24.

2. Cheezum MK, Liberthson RR, Shah NR, Villines TC, O'Gara PT, Lanszburg MJ, et al. Anomalous aortic origin of a coronary artery from the inappropriate sinus of Valsalva. J Am Coll Cardiol. 2017;69:1592-608.

3. Lacour-Gayet F, Anderson RH. A uniform surgical technique for transfer of both simple and complex patterns of the coronary arteries during the arterial switch procedure. Cardiol Young. 2005;15(suppl 1):93-101.

4. Anderson RH, Spicer DE. Fistulous communications with the coronary arteries in the setting of hypoplastic ventricles. Cardiol Young. 2010;20(suppl 3):86-91.

5. Risau W, Flamme I. Vasculogenesis. Annu Rev Cell Biol Dev Biol. 1995;11: 73-91.
6. Red-Horse K, Ueno H, Weissman IL, Krasnow M. Coronary arteries form by developmental reprogramming of venous cells. Nature. 2010;464:549-53.

7. Viragh S, Challice C. The origin of the epicardium and the embryonic myocardial circulation in the mouse. Anat Rec. 1981;201:157-68.

8. Poelmann R, Gittenberger-de Groot A, Mentink M, Bokenkamp R, Hogers B. Development of the cardiac coronary vascular endothelium, studied with antiendothelial antibodies, in chicken-quail chimeras. Circ Res. 1993;73: 559-68.

9. Perez-Pomares JM, Macıas D, Garcıa-Garrido L, Munoz-Chapuli R. The origin of the subepicardial mesenchyme in the avian embryo: an immunohistochemical and quailchick chimera study. Dev Biol. 1998;200:57-68.

10. Palmquist-Gomes P, Guardix JA, Perez-Pomares JM. Avian embryonic coronary arterio-venous patterning involves the contribution of different endothelial and endocardial cell populations. Dev Dyn. 2018;247:686-98.

11. Hackensellner HA. Akzessorische Kranzgeffassanlagen der Arteria pulmonalis unter 63 menschlichen Embryonenseries mit einer grossten Linge von 12 bis 36mm. Zeitschrift für mikroskopischanatomische Forschung. 1956;62:153-64.

12. Bogers AJJC, Gittenberger-de Groot A, Poelmann R, Peault PM, Huysmans HA. Development of the origin of the coronary arteries, a matter of ingrowth or outgrowth? Anat Embryol (Berl). 1989;180:437-41.

13. Theveniau-Ruissy M, Perez-Pomares JM, Parisot P, Baldini A, Miquerol L, Kelly RG. Coronary stem development in wild-type and Tbx 1 null mouse hearts. Dev Dynam. 2016;245:445-59.

14. Arima Y, Miyagawa-Tomita S, Maeda K, Asai R, Seya D, Minoux M, et al. Preotic neural crest cells contribute to coronary artery smooth muscle involving endothelin signalling. Nat Commun. 2012;3:1267.

15. Mellgren AM, Smith CL, Olsen GS, Eskiokac B, Zhou B, Kazi MN, et al Platelet-derived growth factor receptor beta signaling is required for efficient epicardial cell migration and development of two distinct coronary vascular smooth muscle cell populations. Circ Res. 2008;103:1393-401.

16. Perez-Pomares JM, de la Pompa JL, Franco D, Henderson D, Ho SY, Houyel L, et al. Congenital coronary artery anomalies: a bridge from embryology to anatomy and pathophysiology — a position statement of the development, anatomy, and pathology ESC Working Group. Cardiovasc Res. 2016;109:204-16.

17. Rhee S, Chung JI, King DA, D'amato G, Paik DT, Duan A, et al. Endothelial deletion of Ino80 disrupts coronary angiogenesis and causes congenital heart disease. Nat Commun. 2018;9:368-84.

18. Anderson RH, Jensen B, Mohun TJ, Petersen SE, Aung N, Zemrak F, et al. Key Questions relating to left ventricular noncompaction cardiomyopathy-is the Emperor still wearing any clothes? Can J Cardiol. 2017;33:747-57.

19. Anderson RH, Chaudhry B, Mohun TJ, Bamforth SD, Hoyland D, Phillips HM, et al. Normal and abnormal development of the intrapericardial arterial trunks in humans and mice. Cardiovasc Res. 2012;95:108-15.

20. Richardson R, Eley L, Donald-Wilson C, Davis J, Curley N, Alqahtani A, et al. Development and maturation of the fibrous components of the arterial roots in the mouse heart. J Anat. 2018;232:554-67.

21. Chen HI, Poduri A, Numi H, Kivela R, Saharinen P, Mackay AS, et al. VEGF-C and aortic cardiomyocytes guide coronary artery stem development. J Clin Invest. 2014;124:4899-914.

22. Moll M, Michalak KW, Sobczak-Budlewska K, Moll JA, Kopala M Syzmczyk K, et al. Coronary artery anomalies in patients with transposition of the great arteries and their impact on postoperative outcomes. Ann Thorac Surg. 2017; 104:1620-8.

23. Muriago M, Sheppard M, Ho S, Anderson R. The location of the coronary arterial orifices in the normal heart. Clin Anat. 1997;10:1-6.

24. Stephens EH, Gupta D, Bleiweis M, Backer C, Anderson RH, Spicer DE. Path ologic characteristics of 119 archived specimens showing the phenotypic features of hypoplastic left heart syndrome. Semin Thorac Cardiovasc Surg. 2020;32: 895-903.

25. Gerrelli D, Lisgo S, Copp AJ, Lindsay S. Enabling research with human embryonic and fetal tissue resources. Development. 2015;142:3073-6.

Key Words: arterial switch procedure, fistulous communications, Leiden convention, anomalous aortic origin, origin of coronary artery from pulmonary trunk 